\title{
The Effect of the Exposed Aggregate Concrete Pavement on the Reducing Traffic Noise Emission
}

\author{
Han-Young Moon ${ }^{1)}$ and Sang-Wook Ha ${ }^{1)}$ \\ ${ }^{1)}$ Dept. of Civil Engineering, Hanyang University, Korea
}

(Received January 27, 2003; Accepted March 31, 2003)

\begin{abstract}
Portland cement concrete (PCC) pavements are more durable and have superior surface friction compared to most dense-graded asphalt. However, data collected to date generally show PCC pavements to create more noise than asphaltic surfaces. Recent research has shown that some of the new concrete pavement textures are worthy of further examination. One of these, exposed aggregate surfaces, appear to provide better noise quality characteristics as well as good frictional characteristics and durability. In this paper, we considered the relationship between noise level and various textures of exposed aggregate concrete (EAC) pavement by tire impact noise measurement. As the results of that, it was suggested that optimum surface texture and manufacturing condition of EAC in order to reduce tire and pavement interaction noise. Conclusively, we would like to recommend optimum condition of EAC pavement at the respects of materials and treatment. Furthermore, Frequency spectrum as well as A-weighted noise level was also evaluated to analyze properties of noise between PCC and EAC.
\end{abstract}

Keywords : A-weighted noise level, exposed aggregate concrete pavement, frequency spectrum, portland cement concrete pavement, tire impact noise measurement

\section{Introduction}

Environmental issues have become very much part of the political and social agenda in recent years. Among these issues, road traffic noise from automobiles have been causing so serious environmental problem for people living close to roads or in urban areas that the study and solutions to reduce noise have been required. An important and effective strategy to control traffic noise is to reduce the noise produced by individual vehicles. The noise radiated from running road vehicles consists mainly of engine noise, exhaust noise and tire/pavement noise. The tire/pavement noise comprises up to $30 \%$ of total noise and it tends to become dominant under high speed running condition, so the reduction of tire/pavement noise is important for reducing of road traffic noise.

\footnotetext{
* Corresponding author

Tel.: +82-2-2290-0323; Fax.: +82-2-2293-9977

E-mail address: moon77@hanyang.ac.kr
}

Tire vibrations and air pumping are the main generation mechanisms for tire noise on dry pavement. Air pumping is the compression and rapid expansion of air as the air is forced out between the road and the tire tread. Therefore, the road surface and the tire are important factors when considering noise reduction. It has been established that traffic noise reductions may be obtained by appropriate application and design of road surface texture. ${ }^{1)}$

Two broad categories of pavement are generally used for highway construction. These are portland cement concrete (PCC) pavement and asphaltic cement concrete pavement. PCC pavements are the type of paving used on high-volume transportation and highways. The use of PCC pavement is often desirable because of its long service life compared to asphaltic pavements. However, noise level measurements show that PCC pavements create more noise than asphaltic surfaces. Generally, when dense-graded asphalt and PCC pavement are compared, the dense-graded asphalt are quieter by 2 to $3 \mathrm{~dB}(\mathrm{~A})$. Therefore, recent research has suggested some concrete pavements with effective textures to 
reduce noise emission. Exposed aggregate concrete (EAC) pavements have also been evaluated for noise impacts. This PCC surface is made by brushing the surface of the plastic concrete to expose the aggregate, increasing the macrotexture. The frictional characteristics of the PCC pavement surface can be divided into two general groups as microtexture and macrotexture. Microtexture comes primarily from exposing the sand particles in the mortar. Macrotexture refers to grooves and channels formed in the plastic or the hardened concrete. When macrotexture wavelengths increase, tire noise decreases. This is thought to be related to air pumping as previously discussed.

This paper is concerned with the effects of road surface texture on tire/pavement noise by considering EAC pavement with large amount of macrotexture. In conclusion, we would like to recommend optimum production condition of EAC pavement to reduce noise emission.

\section{Materials and methods}

\subsection{Material properties}

(1) Cement

Ordinary Portland Cement (OPC) was used in this study. The specific gravity and specific surface area of cement were 3.15 and $3,150 \mathrm{~cm}^{2} / \mathrm{g}$ respectively. Its chemical composition is given in Table 1 .

\section{(2) Aggregate}

Fine aggregate was gathered from the Han River in Seoul and the coarse aggregate was crushed stones. Since surface texture of EAC pavement is affected by the size of coarse aggregates. It has been found that exposing the aggregate can reduce noise levels, but only if the aggregate sizes are relatively small. In Europe, the general findings were that if aggregate up to a maximum of about $22 \mathrm{~mm}$ was used, the roadway generated more noise than if the maximum aggregate size was limited to $16 \mathrm{~mm}^{2)}$. In this experiment, a maximum size of $13 \mathrm{~mm}$ for the coarse aggregate was adopted to make EAC pavement because $13 \mathrm{~mm}$ coarse aggregate is much easier to obtain in field construction. The physical properties of aggregates employed for test are shown in Table 2.

\section{(3) Chemical admixtures}

The process of manufacturing of EAC includes spraying a setting retarder so that the loose mortar that has not set can be brushed away. Two types of retarders were employed as a chemical admixture to delay setting of surface mortar. The purpose of using a retarder is to get regular depth of exposed aggregate on the surface of concrete pavement by removing a uniform layer of surface mortar.
Retarders adopted in this study are classified as type A or type $B$ according to their main ingredient. The physical properties of the retarders are given in Table 3.

Table 1 Chemical composition of cement

\begin{tabular}{c|c|c|c|c|c|c|c}
\hline \multirow{2}{*}{ Items } & \multicolumn{7}{|c}{ Oxide compositions (\%) } \\
\cline { 2 - 8 } & $\mathrm{SiO}_{2}$ & $\mathrm{Al}_{2} \mathrm{O}_{3}$ & $\mathrm{Fe}_{2} \mathrm{O}_{3}$ & $\mathrm{CaO}$ & $\mathrm{MgO}$ & $\mathrm{SO}_{3}$ & Ig. loss \\
\hline OPC & 20.1 & 6.2 & 3.2 & 62.3 & 3.2 & 2.1 & 1.9 \\
\hline
\end{tabular}

Table 2 Physical properties of aggregates

\begin{tabular}{c|c|c|c|c|c}
\hline Items & $\begin{array}{c}\mathrm{G}_{\max } \\
(\mathrm{mm})\end{array}$ & $\begin{array}{c}\text { Specific } \\
\text { gravity }\end{array}$ & $\begin{array}{c}\text { Absorption } \\
(\%)\end{array}$ & $\begin{array}{c}\text { Fineness } \\
\text { modulus }\end{array}$ & $\begin{array}{c}\text { Unit weight } \\
\left(\mathrm{kg} / \mathrm{m}^{3}\right)\end{array}$ \\
\hline $\begin{array}{c}\text { Fine } \\
\text { aggregate }\end{array}$ & - & 2.62 & 1.10 & 2.40 & 1,527 \\
\hline $\begin{array}{c}\text { Coarse } \\
\text { aggregate }\end{array}$ & 13 & 2.67 & 0.80 & 4.90 & 1,713 \\
\hline
\end{tabular}

Table 3 Physical properties of the chemical admixtures

\begin{tabular}{c|c|c|c}
\hline Items & Main Ingredient & Specific gravity & $\mathrm{pH}$ \\
\hline A type & Phosphate & 1.09 & 1.2 \\
\hline B type & $\begin{array}{c}\text { Regenerated } \\
\text { phosphate }\end{array}$ & 1.18 & 8.0 \\
\hline
\end{tabular}

\subsection{Experimental methods}

(1) Specimen for test

The specimens were $50 \mathrm{~cm} \times 50 \mathrm{~cm} \times 5 \mathrm{~cm}$ concrete plates. The surfaces of specimens were sprayed with retarder when the mixing water on the concrete surface disappeared. The mortar that had not set due to retardation was removed with a brushing apparatus.

\section{(2) Surface hardness test}

Hardness test of the concrete surface was conducted in order to determine the optimum time for brushing. Fig. 1 shows the surface hardness test. It was essential that surface mortar should be removed at the every hardness to investigate the relationship between hardness and exposed depth of aggregate. Shore hardness tester was employed for the test and standardized in KS B 0807. The hardness values were measured five times simultaneously.

(3) Sand patching test

The exposed depth of aggregate as a significant factor to reducing noise was investigated so that noise reduction could be estimated. In order to measure the exposed depth of aggregate, fine sands whose volume was already known were spread on the surface of concrete, and then the depth was calculated by summing the volume of spread sands. It so called sand patching test as shown in Fig. 2. 


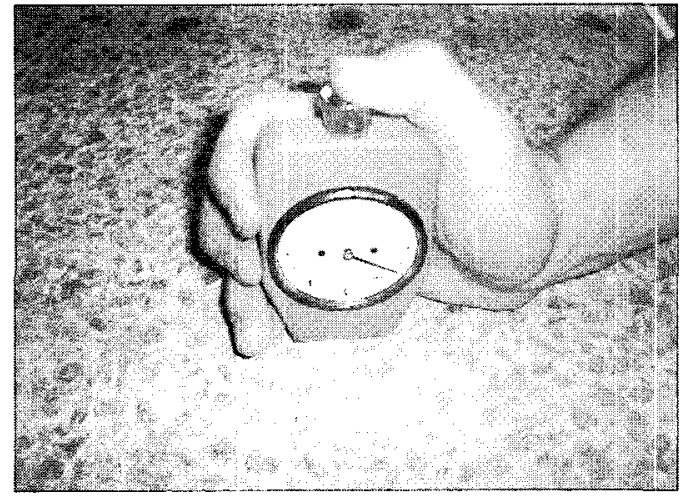

Fig. 1 Surface hardness test

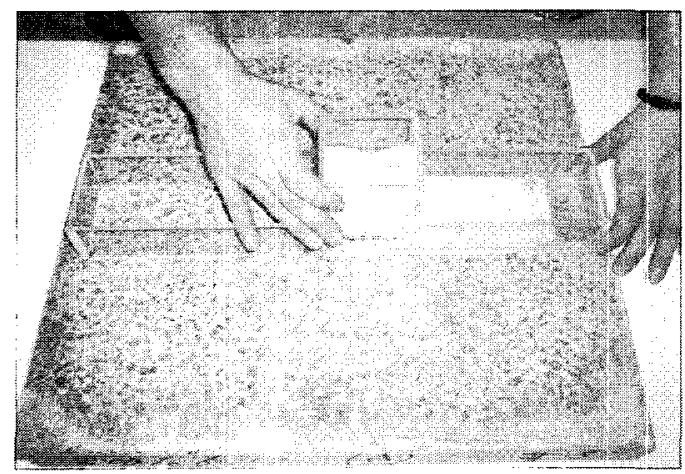

Fig. 2 Sand patching test

(4) Tire impact noise test

Vehicle noise emission is dominated by the noise from the interaction of the tire and pavement surfaces, so called tire/pavement noise. The sound pressure level (SPL) was determined by a tire impact noise test as shown in Fig. 3. In this test, the SPL is obtained from the noise generated when a tire is freely dropped on the specimen at the height of $650 \mathrm{~mm}$. This height is approximates to a vehicle speed of $60 \mathrm{~km} / \mathrm{h}$ when tire impact noise test is compared to the close-proximity method specified in ISO/DIS 11819-2. A description of equipment adopted in this experiment is shown in Table 4.

\subsection{Mixture proportions}

Mixture proportions for this study, based on job mixture

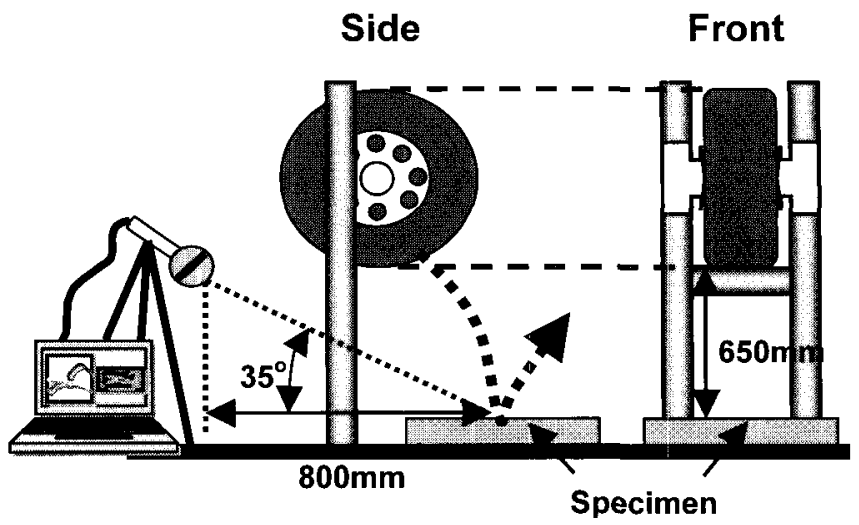

Fig. 3 View of tire impact noise test apparatus

design of concrete pavement (highway of Daejeon Chinju in Korea), were modified to satisfy the manufacturing condition of EAC and are shown in Table 5. The main factor considering in this mixture proportions is the dosage of retarder. The dosage of retarder was varied in each mixture from 100 to $400 \mathrm{~g} / \mathrm{m}^{2}$ and diluted one was also considered from additional effects as well as economical point of view.

Table 5 Mixture proportions of concrete

\begin{tabular}{|c|c|c|c|c|c|c|c|c|}
\hline \multirow{2}{*}{$\begin{array}{r}\mathrm{G}_{\max } \\
(\mathrm{mm})\end{array}$} & \multirow{2}{*}{$\begin{array}{l}\mathrm{W} / \mathrm{C} \\
(\%)\end{array}$} & \multirow{2}{*}{$\begin{array}{l}\mathrm{S} / \mathrm{a} \\
(\%)\end{array}$} & \multicolumn{4}{|c|}{ Unit weight $\left(\mathrm{kg} / \mathrm{m}^{3}\right)$} & \multirow{2}{*}{$\begin{array}{l}\text { AE agent } \\
\left(\mathrm{C}_{\mathrm{wt}} \times \%\right)\end{array}$} & \multirow{2}{*}{$\begin{array}{l}\text { Retarder } \\
\left(\mathrm{g} / \mathrm{m}^{2}\right)\end{array}$} \\
\hline & & & W & $\mathrm{C}$ & $S$ & G & & \\
\hline 13 & 46 & 39 & 159 & 346 & 701 & 1,117 & 0.3 & $\begin{array}{c}100,200 \\
200(50 \%)^{*} \\
400\end{array}$ \\
\hline
\end{tabular}

* Retarder diluted with water of $50 \%$

\subsection{Experimental variables}

(1) Type of retarder

Two types of retarder were employed for investigating the effects of setting retardation according to their ingredient. Type A retarder contained phosphate and the type B retarder contained regenerated phosphate.

(2) Dosage of retarder

It is well known that the setting retardation of concrete is in proportion to the dosage of retarder. In order to remove a

Table 4 Overview of the equipment for noise measurement

\begin{tabular}{c|l}
\hline Items & \multicolumn{1}{c}{ Description } \\
\hline Microphone & $1 / 2$ " Condenser microphone(40AF) \\
\hline Sound analyzer & Symphonie(01dB Ltd.): Dual channel real-time sound and vibration measurement \\
\hline Analyze program & $\begin{array}{l}\text { dBenv32: Combine the features of a data logging integrating sound level meter, a digital tape recorder and a re } \\
\text { time frequency analyzer at the same time. }\end{array}$ \\
\hline Test tire & $\begin{array}{l}\text { Tread pattern featuring attributes of the most popular car "summer tread" tire, intended mainly for use in ter } \\
\text { peratures above } 0{ }^{\circ} \mathrm{C}, \text { Dimensions: } 195 / 70 \mathrm{R} 1491 \mathrm{~T} \text { (Air pressure: 30psi) }\end{array}$ \\
\hline
\end{tabular}


uniform depth of mortar layer, it is very important to determine the best time of brushing for removal of mortar. This depends on the properties and dosage of the retarder. In this experiment, dosage of retarder was varied from $100 \mathrm{~g} / \mathrm{m}^{2}$ to $400 \mathrm{~g} / \mathrm{m}^{2}$, especially in the case of $200 \mathrm{~g} / \mathrm{m}^{2}$, diluted retarder (water : retarder $=1: 1$ ) was also employed to investigate the effects of dilution as the respect of sprayability and economical efficiency.

(3) Curing temperature condition

The hydration of cement is affected by the curing temperature, so it follows that the retardation of concrete would be affected by the curing temperature. The optimum dosage of retader is determined by laboratory tests, but it is difficult to get designed depth of exposed aggregate due to the differences of exterior temperature. Therefore, two types of curing temperature $\left(20^{\circ} \mathrm{C}\right.$ and $\left.30^{\circ} \mathrm{C}\right)$ were adopted in order to evaluate the relationships between retardation and curing temperature.

\section{(4) Curing methods}

The effects of three different curing methods on setting retardation were considered to increase the effects of retarder under the higher curing temperature. Besides exposed to air after placing, polypropylene sheet and wet mat curing were employed to compare effects of setting retardation. It is normally performed that concrete for pavement is usually cured by curing compound or wet mat curing. In this study, the curing with polypropylene sheet was added and this type of curing would be expected prevents rapid evaporation of water on concrete surface in hot weather.

\section{Results and discussion}

\subsection{Sound pressure level}

The sound pressure level measurement was performed in order to determine the relationship between exposed depth of aggregate and the effect of noise reduction. The results are presented in Fig. 4. The sound pressure level measurements at different depths of exposed aggregate show that an exposed depth of $1 \sim 2 \mathrm{~mm}$ produced the lowest sound level values. The sound pressure levels at $1 \sim 2 \mathrm{~mm}$ were approximately $10 \mathrm{~dB}(\mathrm{~A})$ lower than those recorded for conventional concrete. Sandberg and Ejsmont found that the aggregates in newly laid conventional pavement are imbedded in the finer material forming a smooth surface which often causes high levels of air pumping noise. In fact, the noisiest pavement that has ever been measured was a smooth and polished cement concrete pavement. ${ }^{3)}$ Therefore, it is expected that EAC with an exposed depth of $1 \sim 2 \mathrm{~mm}$ can effectively reduce tire/pavement noise.

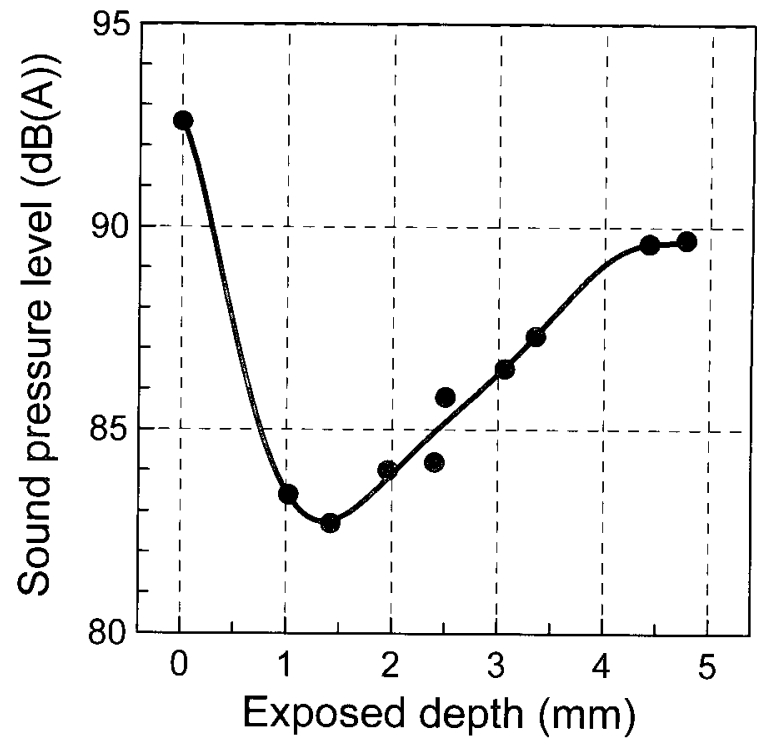

Fig. 4 Exposed depth and sound pressure level.

\subsection{Hardness and exposed depth of aggregate}

In order to obtain a $1 \sim 2 \mathrm{~mm}$ exposed depth of aggregate, it is necessary to consider the proper dosage of retarder, time required for brushing, curing method and method for removing mortar. Firstly, a hardness of concrete was measured to determine the time of removing mortar. This experiment represents an investigation related to obtain designed depth of exposed aggregate by the measurement of surface hardness of concrete. In order to examine relationship between the exposed depth of aggregate and hardness, specimens of varying hardness were made by various dosages of retarder and elapsed time, and then brushed away the loose mortar that has not set at the every hardness of concrete. Exposed depth of aggregate was calculated by sand patching test and removing surface mortar was performed with wire brushing equipment laboratory scaled. At that time, $200 \mathrm{~g} / \mathrm{m}^{2}$ of type A retarder was adopted for setting retardation. These results are presented in Fig. 5. The results show that the exposed depth of aggregate decreased with increasing surface hardness of concrete. Furthermore, it was measured that exposed depth of aggregate was $2 \mathrm{~mm}$ at hardness of 30 and $1 \mathrm{~mm}$ at hardness of 40 . Based on these results, it is possible that exposed depth of aggregate would be estimated by measuring hardness of concrete. Conclusively, the results indicate that a hardness of concrete ranging from $30 \sim 40$ is required to expose the aggregates to a depth of $1 \sim 2 \mathrm{~mm}$.

\subsection{Type and dosage of retarder}

Retarder causes a delay in cement hydration and it is used to obtain a uniform layer of exposed aggregate. In this 


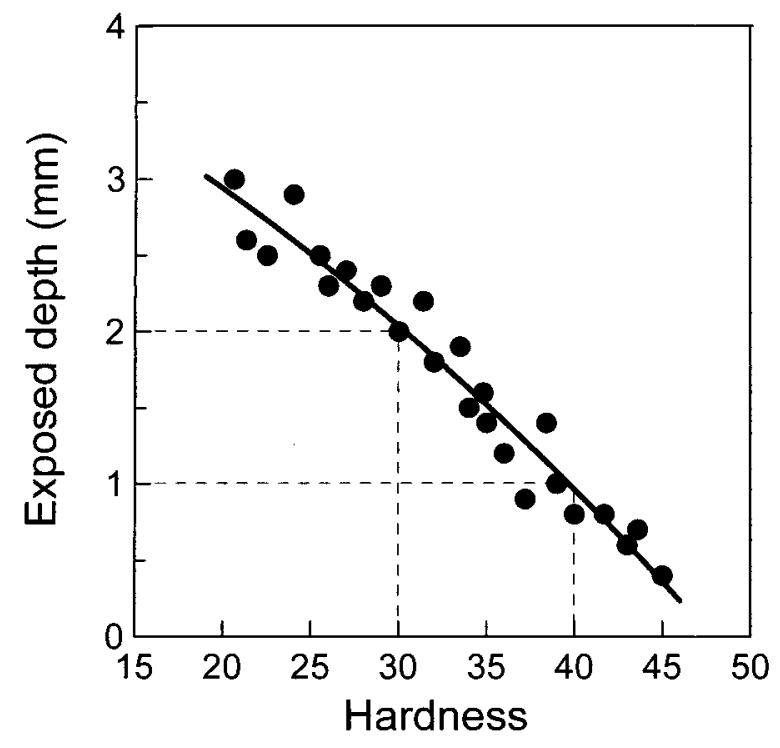

Fig. 5 Hardness of concrete and exposed depth of aggregate

experiment, the effect of retarder type and dosage on aircured concrete specimens was investigated. Two types of retarder, one containing phosphate and the other containing regenerated phosphate, were compared in order to investigate the effect of retardation according to their ingredient. Furthermore, it is known that designed retardation of concrete can only be achieved by adding proper dosage of retarder. Therefore, in order to investigate relationship between the dosage of retarder and hardness, four dosages of each retarder were tested: 100, 200, 200(50\% diluted) and $400 \mathrm{~g} / \mathrm{m}^{2}$. Hardness was measured at 6,12 and 24 hours after spraying retarder. The results are presented in Fig. 6 and 7. There are similar tendencies of results according to dosage of retarder regardless of the retarder type at all ages. The results show that after 6 hours the hardness values are well below the desired range and at 24 hours the hardness values are well above the desired range. It seems that the effect of retardation occurred in proportion to dosage of retarder. However, there are the significant differences of hardness at the ages of 12 hours. The results indicate that Type A retarder more consistently produced surface hardness values in and near the desired hardness range compared to the Type B retarder. The specimens sprayed with 200 and $200 \mathrm{~g} / \mathrm{m}^{2}$ diluted Type A retarder at 12 hours after spraying had hardness values in the desired 30 40 range. For the Type B retarder only the $200 \mathrm{~g} / \mathrm{m}^{2}$ retarder produced hardness values in the desired range. The fact that dosages of Type A were more consistent in producing hardness values in the desired range indicates that it is more stable than the Type B retarder. Zero hour in Fig. 6 and 7 represents the time that the retarder was sprayed. This time is actually four to eight hours after the concrete has been placed. It is

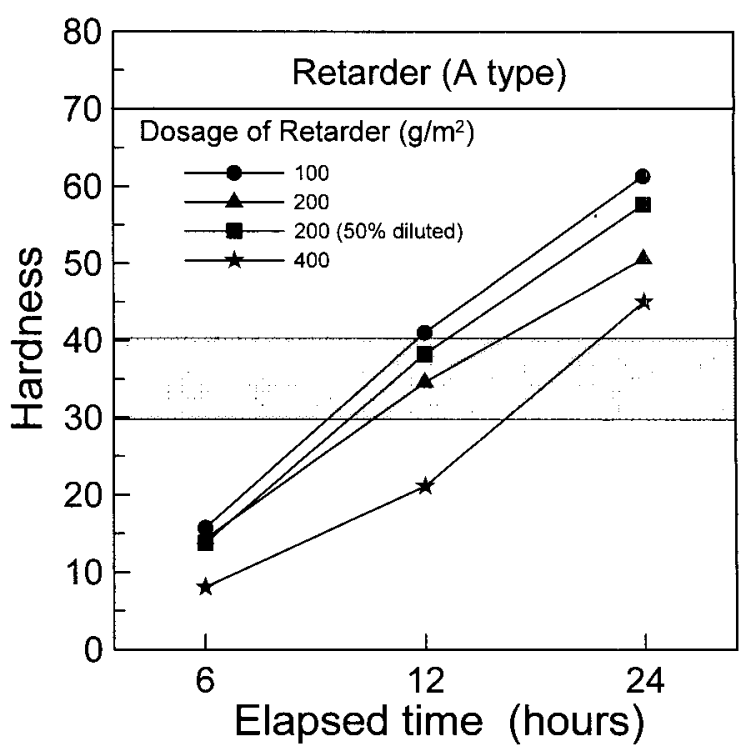

Fig. 6 Hardness of concrete with A type retarder

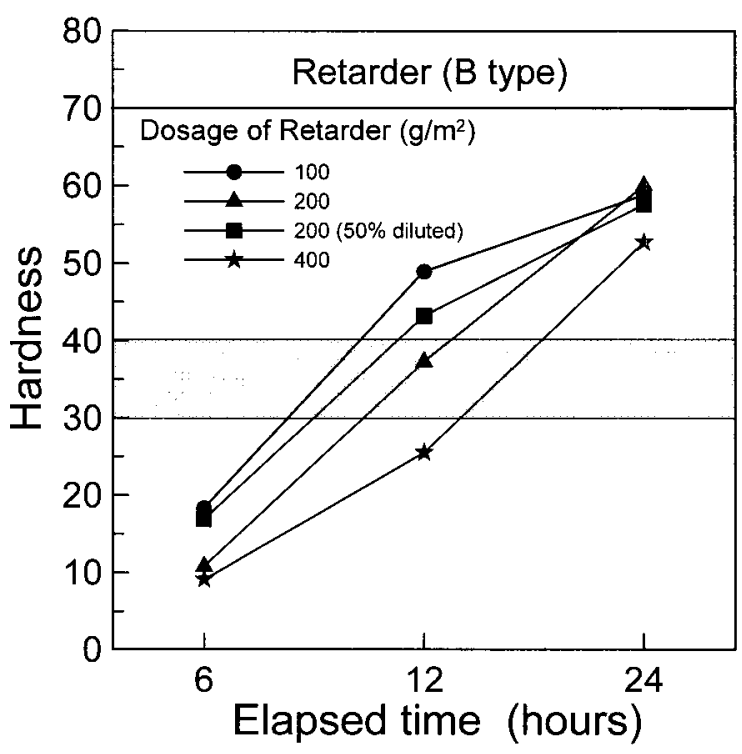

Fig. 7 Hardness of concrete with B type retarder

necessary to wait $4 \sim 8$ hours so that the mixing water on the surface of concrete has disappeared. Therefore, the hardness at 12 hours is actually the hardness after 16 20 hours after the concrete has been placed. After this amount of time the base concrete has had enough time to harden so that it cannot be removed by brushing. In conclusion, adding amount of $200 \mathrm{~g} / \mathrm{m}^{2}$ is suggested to obtain uniform exposed depth regardless of dilution as the respect of construction time and economical efficiency. Since sufficient ages are needed for hardening of base concrete without penetration of retarder, it is supposed that hardness of $30 \sim 40$ could be acquired later than 12 hours after spraying retarder. While the age of concrete is elapsed more than 24 hours, it would be impossible to expect effects of retarder. 


\subsection{Curing temperature condition}

The hardness of specimens cured at 20 and $30^{\circ} \mathrm{C}$ was considered to investigate the relationship between the retardation and curing temperature. The results of hardness test according to curing temperature, which were measured at the ages of 6,12 and 24 hours, are presented in Fig. 8 and Fig. 9.

The hardness for the specimens cured at $30^{\circ} \mathrm{C}$ was greater than the hardness for specimens cured at $20^{\circ} \mathrm{C}$. The hardness of the specimens sprayed with $400 \mathrm{~g} / \mathrm{m}^{2}$ at the

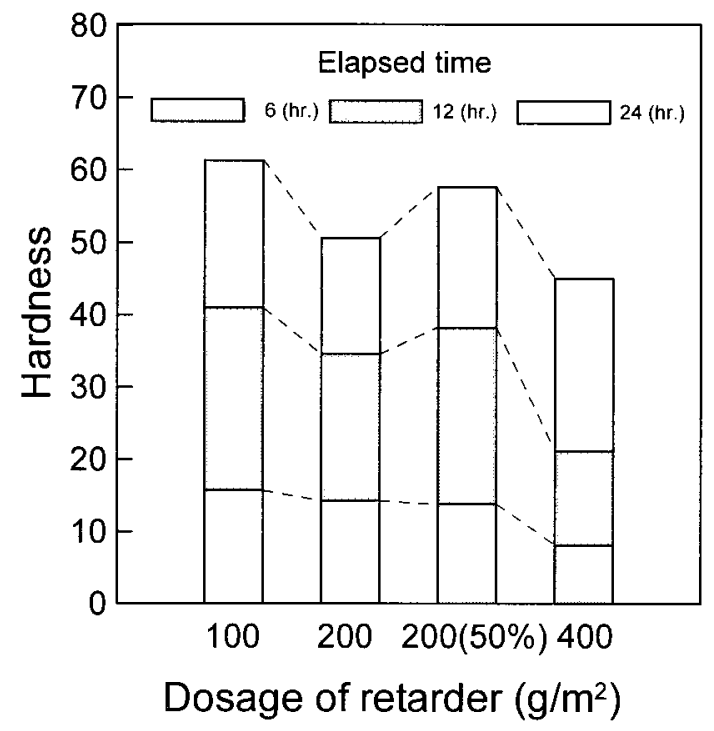

Fig. 8 Hardness of concrete according to curing temperature of $20^{\circ} \mathrm{C}$.

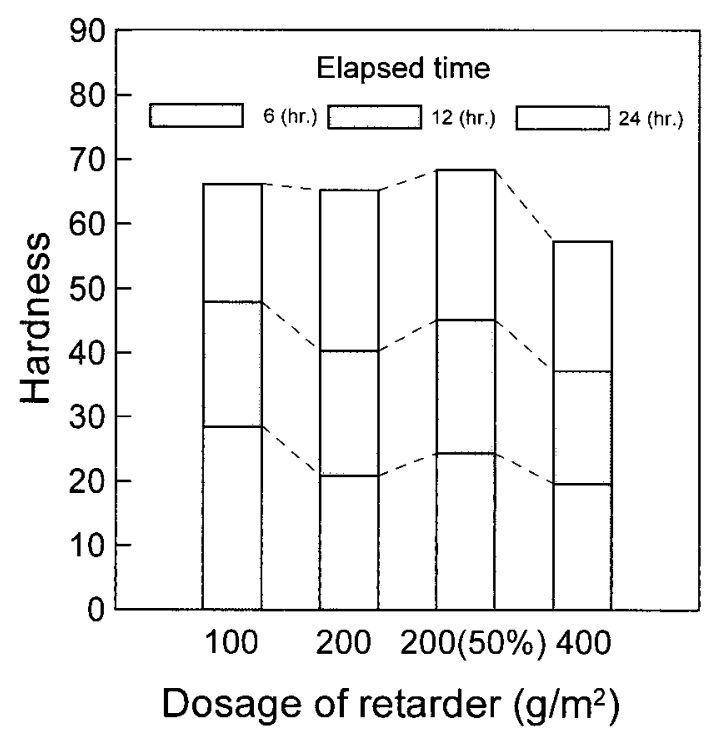

Fig. 9 Hardness of concrete according to curing temperature of $30^{\circ} \mathrm{C}$. curing temperature of 20 and $30^{\circ} \mathrm{C}$ were 21 at 12 hours and 20 at 6 hours respectively. These results indicate that the hardness of concrete cured at $30^{\circ} \mathrm{C}$ was much higher than that of $20^{\circ} \mathrm{C}$ and this tendency was significant in early ages. In general, the results of hardness recorded at the curing temperature of $30^{\circ} \mathrm{C}$ were approximately 10 higher than $20^{\circ} \mathrm{C}$. Furthermore, the results indicate the desired hardness range of $30 \sim 40$ can be achieved at $20^{\circ} \mathrm{C}$ with both the 200 and $200 \mathrm{~g} / \mathrm{m}^{2}$ diluted of Type A retarder. However, at higher temperatures $\left(30^{\circ} \mathrm{C}\right)$ a retarder dosage greater than $200 \mathrm{~g} / \mathrm{m}^{2}$ is needed. A higher dosage of retarder is required at higher temperatures due to the rapid hydration at higher temperatures.

\subsection{Curing method}

Three types of curing methods (exposed to air, polypropylene sheet and wet mat) were used to investigate the effect of curing on retardation at $30^{\circ} \mathrm{C}$ after spraying with 200 and $200(50 \%) \mathrm{g} / \mathrm{m}^{2}$ Type A retarder. These results are shown in Fig. 10. When polypropylene sheet curing is employed instead of conventional curing, surface hardness is decreased regardless of dilution of retarder due to the delayed setting of concrete. It could be explained that the reason is why rapid evaporation was occurred on the surface of concrete at the high temperature. Even in $20^{\circ} \mathrm{C}$, there was also appeared evaporation but not much. The hardness of specimens cured with the polypropylene sheet was lower than the other methods because the polypropylene sheet was more effective in preventing rapid evaporation.

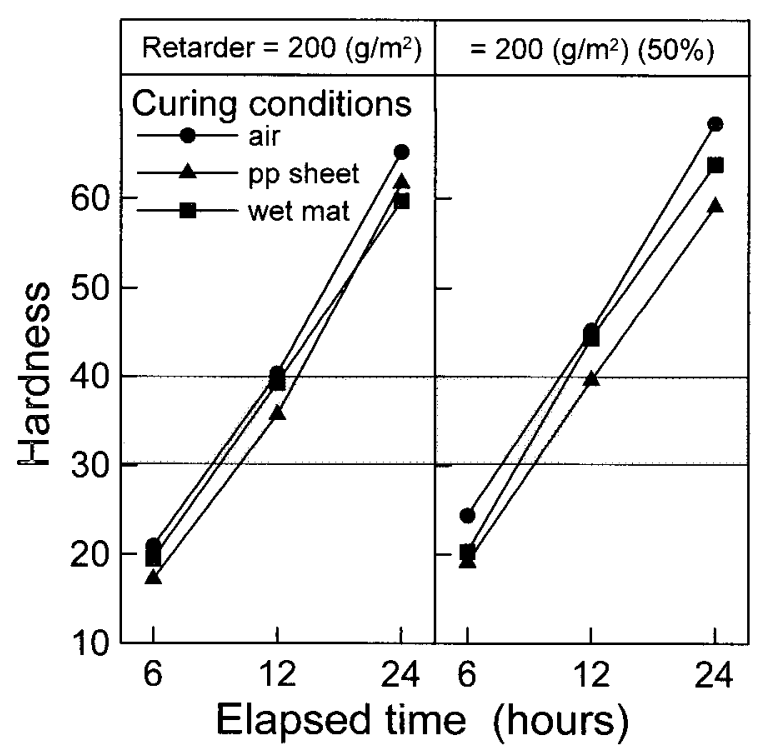

Fig. 10 Hardness of concrete as a function of curing methods. 


\subsection{Noise analysis}

In general, there is slight difference between sound pressure level and real noise due to human's perception. It could be explained by relationships between sound pressure level and frequency. Sandberg \& Ejsmont defined relations texture of concrete and frequency of sound pressure level as follows; ${ }^{3)}$

- Sound pressure levels at low frequencies (below a "crossover frequency") increase with texture amplitude when considering texture within the texture wavelength range $10 \sim 500 \mathrm{~mm}$.

- Sound pressure levels at high frequencies (above a "crossover frequency") decrease with texture amplitude when considering texture within the texture wavelength range $0.5 \sim 10 \mathrm{~mm}$.

It means that the effects of texture on exterior noise are conflicting, depending on how the texture is composed. In general, cross-over frequency is approximately $1,000 \mathrm{~Hz}$ for car tires. Therefore, EAC pavement with large amount of macrotexture is expected to reduce tire/pavement noise at high frequency range $(>1 \mathrm{kHz})$. The results of noise spectra of conventional PCC and EAC pavement are shown in Fig. 11 and Fig. 12 respectively, which represent recordings of the maximum A-weighted noise level and frequency spectrum in one-third octave band.

In the case of EAC pavement, distribution of sound pressure level at high frequencies was much lower than that of PCC pavement as well as lower equivalent sound level. When hearing sensitivity is considered, the frequency content below $500 \mathrm{~Hz}$ is not significant such that the frequency content of tire/pavement is from 500 to $2,000 \mathrm{~Hz}$. Since traffic noise levels are dominated by tire/pavement noise at highway speeds, it is expected that treatment of texture of concrete pavement using EAC could be very effective in reducing traffic noise emission.

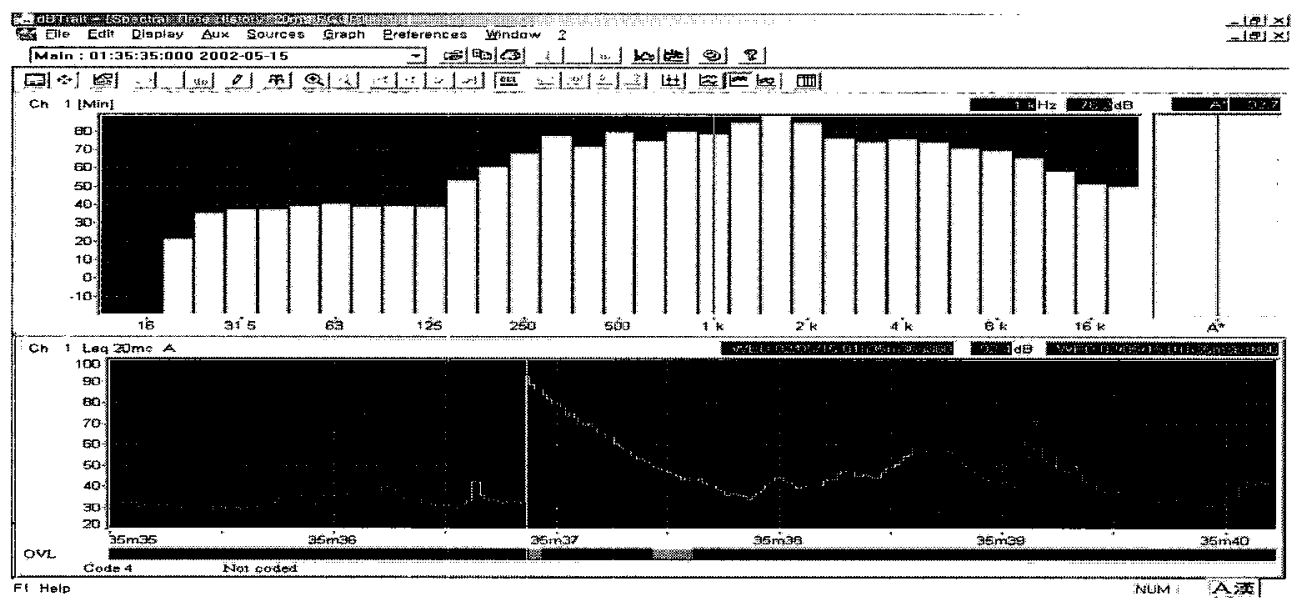

Fig. 11 Noise spectra of conventional PCC pavement.

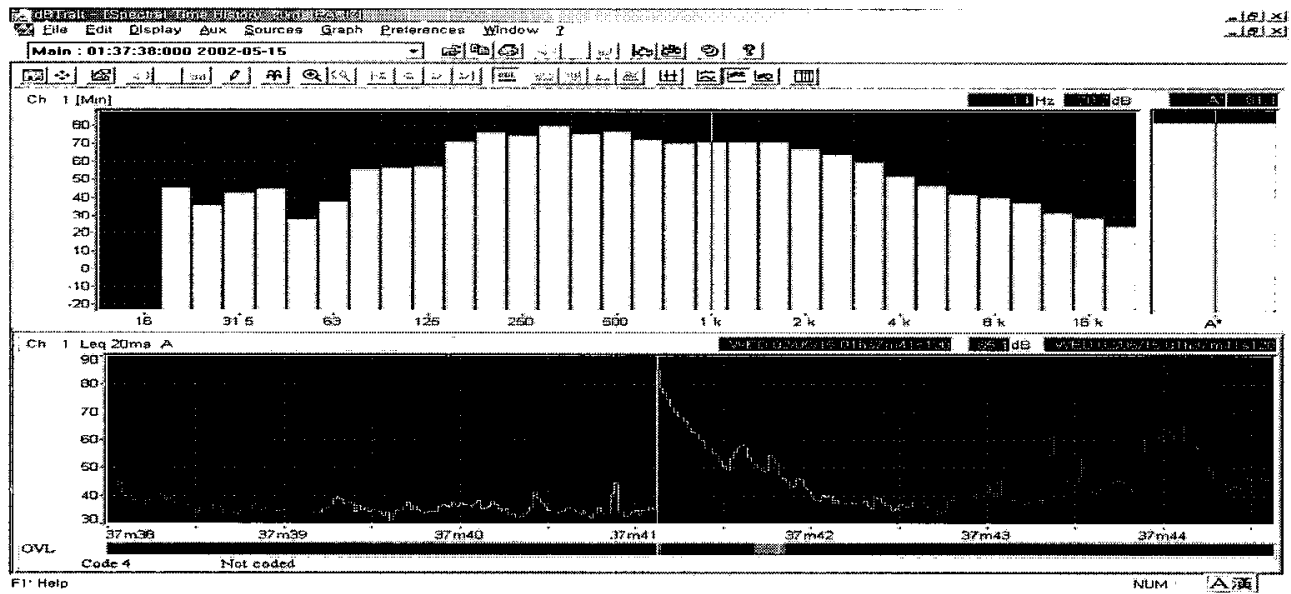

Fig. 12 Noise spectra of EAC pavement. 


\section{Conclusions}

1) The sound pressure level of EAC pavement with an exposed depth of $1 \sim 2 \mathrm{~mm}$ was $10 \mathrm{~dB}(\mathrm{~A})$ lower than that of conventional PCC pavement.

2) Type A retarder was more stable than the Type $B$ and a hardness of 30 40 can be achieved at the age of 12 hours after spraying with a retarder dosage of $200 \mathrm{~g} / \mathrm{m}^{2}$.

3) Concrete cured at $30^{\circ} \mathrm{C}$ was much harder than concrete cured at $20^{\circ} \mathrm{C}$ due to rapid evaporation and hydration. Curing with polypropylene sheet at $30^{\circ} \mathrm{C}$ was effective for obtaining the desired depth of exposed aggregate.

4) The sound spectrum at higher frequencies and the equivalent sound level for $\mathrm{EAC}$ pavement were much lower than for the conventional PCC pavement. This indicates that tire/pavement noise would be significantly reduced on $\mathrm{EAC}$ pavement.

\section{ACKNOWLEDGEMENTS}

This paper was supported by the Ministry of Construction and Transportation.

\section{REFERENCES}

1. Stephen Samuels, "Some Aspects of Tyre/Road Noise from Rigid Pavements," Proceedings of Noise Control Engineering, Washington, October, 1996, pp.73-78.

2. Ulf Sandberg, "Noisy PCC Surface-A New-Found Old Problem?," Proceedings of Noise Control Engineering, Washington, October, 1996, pp.55-60.

3. Ulf Sandberg and Jerzy A. Ejsmont, "Texturing of Cement Concrete Pavement to Reduce Traffic Noise," Noise Control Eng. J. 46 (6), 1998, pp.231-243.

4. H. Y. Moon, S. W. Ha and E. C. Yang, "Properties of Exposed Aggregate Concrete Pavement to Reduce Traffic Noise Emission," Proceedings of the International Conference on Non Conventional Materials and Technologies, Hanoi, March, 2002, pp.149-156.

5. Jonh R. Jaeckel, David A. Kuemmel, Yosef Z. Becker, Alex Satanovsky and Ronald C. Sonntag, "Noise Issues of Concrete-Pavement Texturing," Transportation Research Record, 2000, pp.69-79.

6. Ulf Sandberg, "Noise Trailers of the World-Tools for Tire/Road Noise Measurements with the Close-Proximity Method," Proceedings of Noise Control Engineering, Michigan, April, 1998, pp.71-78.

7. Jill Schlaefer and Robert LaForce, "Noise and Skid Measurements on US285 in the Turkey Creek Canyon Area," Technical Report of Colorado Department of Transportation., 2001.

8. David A. Kummel, Jonh R. Jaeckel and Alex Satanovsky, "Investigative Study of the Italgrip System: Noise Analysis," Final Report WI/SPR-02-00., 2000. 